\title{
Application of geoaccumulation index and enrichment factors on the assessment of heavy metal pollution in the sediments.
}

\begin{abstract}
An investigative study was carried out in Langat River to determine the heavy metal pollution in the sediment with 22 sampling stations selected for the collection of sediment samples. The sediment samples were digested and analyzed for extractable metal $((48) \mathrm{Cd},(29) \mathrm{Cu}$, (30)Zn, (33)As, (82)Pb) using the Inductively Coupled Plasma-Mass Spectrometry (ICP-MS). Parameters, such as $\mathrm{pH}$, Eh, electrical conductivity (EC), salinity, cation exchange capacity (CEC) and loss on ignition (LOI) were also determined. The assessment of heavy metal pollution was derived using the enrichment factors (EF) and geoaccumulation index (I(geo)). This study revealed that the sediment is predominantly by $\mathrm{As}>\mathrm{Cd}>\mathrm{Pb}>\mathrm{Zn}>\mathrm{Cu}$. As recorded the highest $\mathrm{EF}$ value at 187.45 followed by $\mathrm{Cd}$ (100.59), $\mathrm{Pb}$ (20.32), $\mathrm{Zn}$ (12.42) and $\mathrm{Cu}$ (3.46). This is similar to the $\mathrm{I}(\mathrm{geo})$, which indicates that the highest level goes to As (2.2), exhibits moderately polluted. Meanwhile, $\mathrm{Cd}$ recorded 1.8 and $\mathrm{Pb}(0.23)$, which illustrates that both of these elements vary from unpolluted to moderately polluted. The $\mathrm{Cu}$ and $\mathrm{Zn}$ levels are below 0, which demonstrates background concentrations. The findings are expected to update the current status of the heavy metal pollution as well as creating awareness concerning the security of the river water as a drinking water source.
\end{abstract}

Keyword: River; Sediment; Enrichment factors; Geoaccumulation index. 